\title{
The Conception of Tunisian Student Teachers of the Formative Role of the Cooperative Teacher's
}

\author{
Wadii Zayed1,2, Naila Bali1,2, Nizar Souissi, ${ }^{1,2}$, Jean François Desbiens ${ }^{3}$ \\ ${ }^{1}$ High Institute of Sport and Physical Education of Ksar Saîd, University la Manouba, Tunis, Tunisia \\ ${ }^{2}$ Tunisian Research Laboratory "Sport Performance Optimization", Tunis, Tunisia \\ ${ }^{3}$ Education Departments, Sherbrooke University, Quebec, Canada \\ Email: Zayed-wadii@hotmail.com, naila.bali@laposet.net
}

Received 19 May 2015; accepted 23 June 2015; published 25 June 2015

Copyright (C 2015 by authors and Scientific Research Publishing Inc.

This work is licensed under the Creative Commons Attribution International License (CC BY). http://creativecommons.org/licenses/by/4.0/

CC) (i) Open Access

\begin{abstract}
Tutoring is located at the crossroads of academic and practical logic; it's defined as a training device in the workplace. Indeed, much research has demonstrated the importance of the accompaniment of the cooperative teacher's (CT) on their practicum. The CT is contributing to the training by the advice and support. Our research "the formative role of CT" seeks to explore the accompaniments practices in initial training of PE-STs. This study includes a qualitative analysis which aims to identify the conception PE-STs of the role of CT for whom they are responsible for training. It's a descriptive/exploratory methodology based on a questionnaire consisting of open questions to clarify the latent construct "practical accompanying" and gives PE-STs the opportunity to share their concepts and concerns on issues, such as professional training, accompanying practices and CT role. Data are collected with forty PE-STs during professional training in Level 3 (third year, BAC + 3). PE-STs justify their preoccupation by four categories in which we have grouped the different types of responses. The PE-STs are more interested by problems of the knowledge (32.39\%) and interventions $(30.99 \%)$ of CT. They believe that there's a difference between the conception of the role of CT by PE-STs before and during the internship.
\end{abstract}

\section{Keywords}

Professional Training, Student Teachers, Tutor, Practical Accompanying

\section{Introduction}

In the literature, the studies don't lack of reflection on the accompaniments practices during the initial training 
of PE-ST but few studies measure and analyze their effects. However, analysis of the tutorial activity has taken an interest in the field of professional training (Martineau \& Presseau, 2003; Maela, 2009; Desbiens et al., 2009; Perez-Roux, 2012) and the Higher Institute of Sport and the physical Education (ISSEP) to Tunis (Bali, 2005; Bali, 2013; Bali et al., 2013; Bali \& Souissi, 2015; Bali, 2015; Zayed \& Bali, 2015). According to Bergevin (2007), mentoring results in a personal and professional relationship between the mentor and mentee. Mentors are also known as: experienced teachers, accompanists or supervisors. Mentees are different names like: beginning teachers or even novices protected. Bergevin (2007) adds that there are many definitions of the term "mentoring". He divided these definitions depending on the type of process to which they refer: accompaniment process, teaching process, interaction and relational process. In this context, the CT plays a fundamental role in facilitating their integration in the professional context (Lévesque \& Gervais, 2000; Martineau \& Presseau, 2003; Jorro, 2007; Perez-Roux, 2012; Bali, 2014). According to Bremond (2013) the terms "trainer" and "learner" refer to asymmetric roles, one receiving what the other initiates. These roles are distributed in situations of training and have an influence on the content of discussions and training process. For its part, the CT must have a style, develop a training contract, master interviewing techniques and make the evaluation (Carlier, 2002). Boutet (2002) lists some characteristics of a good CT: the experience, the confidence, the openness to theoretical contributions and reflection, the coherence, the acceptance to question and to be questioned. To be a CT, one must be able to explain his thinking; to work in teams and to share tasks also have interpersonal skills, attention to each other and positive confrontation. However, Brau-Antony et al. (2011) confirm that mentoring is a difficult function to perform. They note that the competencies required for the tutor function are different from teaching students. Usually after piloting the session, when a pedagogical act was not expected performed by PE-ST, CT explained his expectations, which appeared to him right, from a teaching behavior or classroom management. At that time, PE-ST noted the comments made and tried to show in a future session her "competence" to do as CT asked. Boulet \& Pharand (2008) add that PE-ST wants to be guided and supervised. They want to take the initiative and accept their errors are reported. Rayou \& Ria (2009) argue that new teachers rarely have an awareness of the reasons for the failure or success of their interventions. Mouton (2009) finds that there is a great illusion to believe that $\mathrm{CT}$ is able to respond effectively to the requirements of a trainee engaged with a problem situation. He added that the CT is neither a scientist nor an expert, but a professional who organizes a training environment in a role to introduce PE-STs in the teaching profession.

The objective of this study is to highlight the conception of PE-STs of the formative role of CT. We will define the nature of the responses of PE-STs. Do we know actually what is learned in usually termed the "the formative role of CT"? I will be interested in this question in the field of practical accompanying of the PE-ST in Tunisian secondary schools. In order to operationalize research questions, we have developed the following hypotheses: The PE-STs are more interested by problems of the behavior and the relationship of CT. There's a difference between the conception of the role of CT by PE-STs before and during the internship.

\section{Methodology}

\subsection{Participants}

The participants had accepted to participate in this study. 40 PE-STs (20 men and 20 girls) indicated in Table 1 were selected from total 315 PE-STs studied in the Higher Institute of Sport and Physical Education (ISSEP) Tunis (there are only 3 ISSEP in Tunisia each having their own teaching practice modality), whcih is a public Institute in Tunisia. All participated in this study were voluntarily. Participants were chosen taking into account the location of the school, the teaching level and sex of CT. They were recruited from a single Higher Institute of Sport (Tunis). The sample of participants consisted of the PE-ST (third year, BAC +3 ) who taught level 1 and 2 (first year of secondary education and the second year). All were aged between ( $21 \pm 1$ years old) registered in an introductory course to professional training, in Tunisia introductory we call the course to practice pedagogy (introductory practicum applied to pedagogy), that share in the last year of the Fundamental of Physical Education License. This activity has introducted professional life took place in schools with mixed age students (12-15 years old students) from a rural area in Tunis very engaged in professional training. The activity lasted two semesters, four hours per week on Tuesday or Thursday for a cumulative total time of 116 hours of teaching. Participants are not paid to participate in the research. They were not informed of the purpose and conception of the research.

The CT has teaching experience about 10 years and experience in the formation of the PE-ST between 5 and 10 years. 
Table 1. Sample of Tunisian PE-ST.

\begin{tabular}{cc}
\hline & PE-ST \\
\hline Questioning & 40 \\
Men questioned & 20 \\
Girls questioned & 20 \\
Aged & Between 20 and 22 years old \\
Level of study & BAC +3 \\
\hline
\end{tabular}

Three main reasons justified the choice of this sample. Firstly, this study is part of the professional training of PE-ST. The CT is considered as a person of alternating between the university and the training environment. Which will allow us to see the nature of PE-ST conceptions of practical accompanying of CT and to understand the formative role of CT. Secondly, there is a social difference between the academic and professional? This allowed us to hypothesize the practical accompanying of CT in the integration and learning of PE-ST. This difference could influence the teaching practices of student teachers. Thirdly, this study is part of the academic program. Enabled to us hypothesize of the practical accompanying of CT should accord with this orientations and promote student learning. Our work sample meets these three parameters as indicated in Table 1.

\subsection{The Open Question}

We used open questions (they allow the collection of opinions and personalized answers) to clarify the latent construct "practical accompanying" and gave PE-STs the opportunity to share their concepts and concerns on issues such as professional training, accompanying practices and CT role. The questions focus on the conception of the role of CT by PE-STs before and during the internship. PE-STs are questioned by allowing them the freedom to respond, they can express themselves at their ease. The interview was scheduled for 45 minutes, according to the same considerations; the duration varies slightly from one subject to another.

\subsection{Data Collection}

Data collection was performed in three phases. The first is an interview with PE-STs in order to have data that can be useful in this study as their age. At this meeting, we presented to the PE-STs the different steps of this research to know the phases of the questionnaire. The second is the questions focus on the conception of the role of CT by PE-STs before the internship. Finally, the third is the questions focus on the conception of the role of CT by PE-STs during the internship and the difference between the two times.

\subsection{The Formation of the Corpus}

After the collection of the questionnaire data conducted among PE-STs (step 1), we have proceeded to the transcription of each questionnaire responses and reported in the grid (step 2). This grid has allowed us to categorize the responses of PE-STs. Finally, the third step is the linking of analyzes from different investigative techniques. We crossed the data collected during the first two steps. This categorization allowed us to approach through what the PE-ST responds and says.

\section{Result and Discussion}

\subsection{Result}

After a didactic transcription of the contents of the response of sixty PE-STs before the professional internship, we conducted a coding. We developed four categories in which we have grouped the different types of response:

(i) "The behavior of CTs" whenever the PE-STs talk about Assiduity, Psychological condition, PE-ST motivation and communication skills to provide a model of the behavior of the CT. In sub category "assiduity", PE-STs declare that the CT should not be absent, come on time to school before the student and must be present all along the day. In sub category "psychological condition", PE-STs report that the CT must be polite with PE-ST, supports him when he makes mistakes, sustains the PE-ST and gave him the autonomy. In sub category "PE-ST motivation”, PE-STs respond that the CT must be encourage the PE-ST and positive his advice. In sub category "communication skills", PE-STs say that the CT must have a scientific discourse with PE-ST. 
(ii) "The relationship of CT" whenever the PE-ST states that the CT must have a good relationships with the PE-ST, the administration and student. In sub category "relationships with the PE-ST", PE-STs declare that the CT must have a good relationship with the PE-ST and take in to account that the PE-ST is not an experienced teacher. In sub category "relationships with the administration”, PE-STs reports that the CT must integrate and help the PE-ST to solve the problems with the administrative personal. In sub category "relationships with the student “, PE-STs respond that the CT must help PE-ST in the mastery of students.

(iii) “The knowledge of CT” whenever PE-STs talks about teaching style, academic and experiential knowledge. In sub category “Academic knowledge”, PE-STs say that the CT must have a mentoring training, informed of the development of courses at the institute, transmits theoretical knowledge, have a training program and must helping the PE-ST t to research the selection of situations. In sub category "experiential knowledge", PE-STs respond that the CT must have a teaching experience and Transmits practice instructions. In sub category "teaching style", PE-STs declare that the CT must have a teaching style and a training process.

(iv) "The interventions of CT" whenever the PE-STs talks about access to land and material, correction of the PE-ST document, observation of the session and advice after the session. In sub category "access PE-ST to land and material”, PE-STs say that the CT must present the equipment of the establishment and provides favorable conditions, terrain and equipment to the PE-STs. In sub category “correction of the PE-ST document”, PE-STs report that the CT must correct pedagogical sheet, the cyclical programming, the report of sessions and the class journal. In sub category "Observation of the session”, PE-STs declare that the CT must observe the entire session, take notes in the observation and should not intervene in the piloting of the session. In sub category "advice after the session”, PE-STs say that the CT must obligatorily make a feedback, outline the PE-ST errors as feedback, respond to PE-ST questions and respect PE-ST ideas.

During professional internship we conducted a coding after a didactic transcription of the contents of the response of sixty PE-STs. We developed four categories in which we have grouped the different types of response:

(i) " The behavior of CTs "whenever the PE-STs talk about Assiduity, Psychological condition, PE-ST motivation and communication skills to explore the behaviors deflected of the CT. In sub category "assiduity", PE-STs declare that the CT is absent from formation and comes late to school after the student. In sub category “psychological condition”, PE-STs report that the CT must be neglect PE-ST, get angry, behaves aggressively and don't support the PE-ST. In sub category "PE-ST motivation", PE-STs respond that the CT uses physical and verbal violence with students and requires the PE-ST to do, don't encourage and demoralizes PE-ST and don't congratulate the PE-ST despite the effort put. In sub category "communication skills", PE-STs say that the CT transmits the information with an understandable way, sets all the time negative remarks and underestimates the PE-ST work.

(ii) "The relationship of CT" whenever the PE-ST states that the CT don't have a good relationships with the PE-ST, the administration and student. In sub category "relationships with the PE-ST”, PE-STs declare that the CT confuses personal behavior and professional, don't behave with PE-ST in the same way and requires the PE-ST to make secondary tasks. In sub category "relationships with the administration", PE-STs report that the CT doesn't present the PE-ST at the administrative personal. In sub category "relationships with the student”, PE-STs respond that the CT doesn't help the PE-ST establish a good relationship with students and pushes the PE-ST to exclude students.

(iii) “The knowledge of CT" whenever PE-STs talks about teaching style, academic and experiential knowledge. In sub category “Academic knowledge”, PE-STs say that the CT don't control what he says, don't differentiate between didactics and pedagogy, don't know how prepared a report of the session and have a low theoretical knowledge. In sub category “experiential knowledge “, PE-STs respond that the CT transmits his experience of sports training and general knowledge. He compared his experience of the student experience. In sub category “teaching style”, PE-STs declare that the CT doesn't have an accompaniment style and uses a traditional method.

(iv) "The administrative tasks" whenever the PE-STs talks about the correction of the PE-ST document, the observation of the session, the advice after the session and the evaluation. In sub category "correction of the PE-ST document”, PE-STs report that the CT doesn't correct the pedagogical sheet and the class journal. In sub category “Observation of the session”, PE-STs declare that the CT don't observe the session, only a part and intervene in the piloting of the session. In sub category "advice after the session", PE-STs say that the CT does not make a feedback after the pilot session, emits only feedback on mastery of time and class, Leaves other teachers to make feedback and don't respect PE-ST ideas. In sub category “evaluation “, PE-STs say that the CT is not objective in the allocation of the notes of students. 


\subsection{Discussion}

\subsubsection{Conception of PE-STs of the Role of CTs before Professional Training}

The concerns of PE-STs related to different categories defined before the training courses are in the order: The interventions of CT (41.22\%), the behavior of CT (27.70\%), the knowledge of CT (22.30\%) and the relationship of CT (8.78\%) indicated in the Figure 1.

The results reveal that the major expectation of practical accompaniment of CTs that the PE-STs conceive seems to be:

The interventions of CT (41.22\%) indicated in the Table 2: whenever the PE-STs talks about:

Access to land and material: One of PE-ST said: "The student has an important role. He must put the material and the land available to the PE-STs" (PE-ST 16), correction of the PE-ST document: some of PE-ST said: "The CT must make a daily followed" (PE-ST 11), "must control the class journal, notebook feedback" (PE-ST 8), "Check the theoretical support” (PE-ST 4), "corrects the documents of the PE-ST" (PE-ST 6), "they must correct pedagogical sheet” (PE-ST 19), "corrects the cyclical programming” (PE-ST 21).

Observation of the session: some of PE-ST said: "The student must follow the student to correct his faults" (PE-ST 4). "During the observation, it should take note to tell me for in feedback" (PE-ST 18). "He must leave the trainee pilot the meeting alone (PE-ST 19)."He must not intervene in the piloting of the session" (PE-ST 20). "I don't like the idea that the CT intervenes during the session" (PE-ST 40). "Through observation, he must correct and give advice to the intern” (PE-ST 32).

Advice after the session: some of PE-ST said: "The CT must obligatorily make a feedback, transmitting instructions and give solution to the difficulties encountered during the pilot session" (PE-ST 7). "It must transmit many instructions. He must explain how the teacher manages students" (PE-ST 1). "He must criticize the PE-ST to let him know his faults" (PE-ST 6). "He should make a detailed feedback (PE-ST 19), corrects my faults, answer on my questions and give me solutions" (PE-ST 25). "He must explain during the feedback for that PE-ST learns from his knowledge and experience” (PE-ST 27).

According to Faingold (2006) the important points of professional training are the quality of discussion, the listening, the type of questions and the sincerity of the relationship between PE-ST and CT.

Boutet \& Pharand (2008) remarks that PE-STs want to guided and supervised. They wish to take the initiative and accept that their errors are reported. Rayou \& Ria (2009) argue that beginning teachers rarely have a clear awareness of the reasons for the failure or success in of their interventions.

Boutin \& Camaraire (2001) state that if the criteria for selection of CTs based on the pole model (teaching experience, proven expertise, team spirit and sensitivity to the life of the school), the pole trainer of CT remains high (observation skills, analytical and critical thinking). Boutet (2002) set out a list of characteristics of a performed CT: experience, confidence in his means, openness to theoretical contributions and reflection, coherence, accepting to be interviewed and questioned. To be a CT, one must be able to explain his thinking; to work in teams and to share tasks also have interpersonal skills, attention to each other and positive confrontation.

Trohel et al. (2004) described the forms of joint commitments of the CT and the PE-ST during their interaction during post-lesson interviews, giving a privileged viewpoint of each actor involved in these interactions.

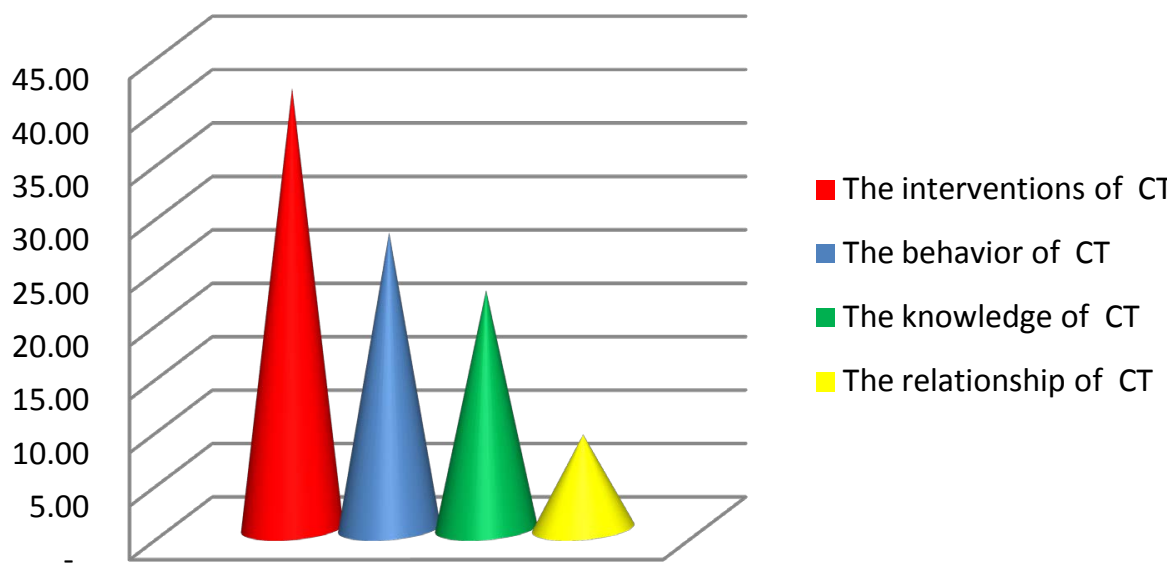

Figure 1. The concerns of PE-STs of the role of CTs before professional training. 
Table 2. Analysis grid of conception of PE-STs of the role of CTs before professional training.

\begin{tabular}{|c|c|c|c|c|}
\hline Category & Sub category & The items & Total & $\%$ \\
\hline \multirow{11}{*}{$\begin{array}{c}\text { 1-The behavior } \\
\text { of CT } \\
\text { TOTAL: } 41 \\
27.70 \%\end{array}$} & \multirow{3}{*}{ Assiduity } & Not absent & 1 & 0.67 \\
\hline & & Come on time to school before the student & 9 & 6.09 \\
\hline & & Present all along the day & 11 & 7.44 \\
\hline & \multirow{4}{*}{ Psychological condition } & Polite & 1 & 0.67 \\
\hline & & Supports the PE-ST when he makes mistakes & 1 & 0.67 \\
\hline & & Sustain the PE-ST & 1 & 0.67 \\
\hline & & Gives autonomy to the PE-ST & 1 & 0.67 \\
\hline & \multirow[t]{2}{*}{ PE-ST motivation } & Encourages the PE-ST & 9 & 6.09 \\
\hline & & Ct is positive & 1 & 0.67 \\
\hline & \multirow[t]{2}{*}{ Communication skills } & Has a scientific discourse & 6 & 4.06 \\
\hline & & & 41 & 27.70 \\
\hline \multirow{9}{*}{$\begin{array}{c}\text { 2-The relationship } \\
\text { of CT } \\
\text { TOTAL: } 13 \\
8.78 \%\end{array}$} & \multirow{2}{*}{ With the PE-ST } & Having good relationship & 2 & 1. 35 \\
\hline & & Take into account that the PE-ST is not a teacher wholly & 1 & 0.67 \\
\hline & \multirow[t]{2}{*}{ With the administration } & Integrate the PE-ST with the administrative personal & 3 & 2.03 \\
\hline & & Help the PE-ST to solve the problems with administration & 1 & 0.67 \\
\hline & \multirow[t]{4}{*}{ With the student } & Help PE-ST in the mastery of students & 6 & 4.06 \\
\hline & & & 13 & 8.78 \\
\hline & & Must have mentoring training & 8 & 5.41 \\
\hline & & Informed of the development of courses at the institute & 1 & 0.67 \\
\hline & \multirow[t]{3}{*}{ Academic knowledge } & Transmits theoretical knowledge & 5 & 3. 38 \\
\hline \multirow{11}{*}{$\begin{array}{c}\text { 3-The knowledge } \\
\text { of CT } \\
\text { TOTAL: } 33 \\
\text { 22. } 30 \%\end{array}$} & & Must have a training program & 1 & 0.67 \\
\hline & & Helping the PE-ST t to research the selection of situations & 3 & 2.03 \\
\hline & Experiential & Has teaching experience & 5 & 3. 38 \\
\hline & knowledge & Transmits practice instructions & 6 & 4.06 \\
\hline & Teaching style & Must have a teaching style, a training process & 4 & 2.70 \\
\hline & & & 33 & 22. 30 \\
\hline & Access PE-ST to & Presents the equipment of the establishment & 2 & 1. 35 \\
\hline & land and material & Provides favorable conditions, terrain and equipment & 3 & 2.03 \\
\hline & & Correct pedagogical sheet & 23 & 15.55 \\
\hline & Correction of the & Correct the cyclical programming & 2 & 1. 35 \\
\hline & PE-ST document & Correct the report of sessions & 2 & 1. 35 \\
\hline \multirow{9}{*}{$\begin{array}{c}\text { 4-The interventions } \\
\text { of CT } \\
\text { TOTAL: } 61 \\
41.22 \%\end{array}$} & & Correct the class journal & 4 & 2.70 \\
\hline & & Observe the entire session & 5 & 3.38 \\
\hline & $\begin{array}{l}\text { Observation } \\
\text { of the session }\end{array}$ & Takes notes in the observation session & 2 & 1. 35 \\
\hline & & Should not intervene in the piloting of the session & 3 & 2.03 \\
\hline & & Outlines the PE-ST errors as feedback & 6 & 4.06 \\
\hline & Advice after & Responding to student questions & 7 & 4.73 \\
\hline & the session & Must obligatorily make a feedback & 1 & 0.67 \\
\hline & & Respect PE-ST ideas & 1 & 0.67 \\
\hline & & & 61 & 41.22 \\
\hline Total & & & 148 & \\
\hline
\end{tabular}


They noticed that the CT is malformed in the role of tutor; they act on the basis of their professional experience in teaching physical education.

Beau-Antony et al. (2011) are moving in this direction, they study the characteristics of the professional activity of the CT to identify the difficulties encountered when supervising PE-ST. They showed that tutoring is a difficult function to perform because you have to engage the best in a mission for which most of the time it's poorly trained. Carlier (2002) proposes to bring the CT and PE-ST to exchange about academic knowledge. Avoid introducing his trainee that: "Forget what you learned in college".

Carlier (2002) suggests that CT recognize the existence of two types of knowledge (academic and practical) and try to exploit them optimally. It presents two distinct worlds that everything seems to separate: the academic world on the one hand and professional reality, on the other. In addition, Carlier (2002) proposed to establish a communications contract with the trainee to guide the verbalization of his action. Through questioning that he put in place, the CT enters the psychic intimacy of the trainee.

Vandercleyen et al. (2013) shows the success of the professional training depends by the type of intervention of the CT. They highlight in particular the dual role of the CT, to be able to explain their own pedagogical concepts to the PE-ST and help the latter to clarify his thoughts, his actions and his decisions.

The behavior of CT (27.70\%) indicated in Table 2: whenever the PE-STs talks about:

Assiduity: The PE-STs reported that the CT must be responsible, serious and punctual and should not be absent. It must be present throughout the day of the internship to help and train that. Some of PE-ST said: "It's necessary that the CT is responsible; he must come on time" (PE-ST 1). "It must be punctual (PE-ST 15). It should not come late or absent" (PE-ST 17). "The CT has to help me; he must arrive on time (PE-ST 20). It must be present all the time to help me and train me” (PE-ST 22). "The CT must be serious, always present, is no delay. It must arrive before the PE-ST" (PE-ST 6).

Psychological condition: PE-STs state that CTs must be polite. He must respect and support PE-STs when they make mistakes. Some of PE-ST said: "CT must respect the student (PE-ST 15).”It must be polished with the PE-ST" (PE-ST 18). "CT has supported me as I make mistakes” (PE-ST 21).

PE-ST motivation: PE-STs say that the CT must be positive. It must support, encourage and motivate the PE-ST. Some of PE-ST said: "The CT must be positive (PE-ST 5). It should support and encourage the student" (PE-ST 25). "CT is the most important link in the training chain. It should encourage and motivate PE-ST" (PEST 32).

Communication skills: PE-STs say that the CT must emit feedback with an attractive way. Some of PE-ST said: "CT should emit a feedback in an attractive and positive way" (PE-ST 18).

According to Parmentier (2003) it should be respect the intensity variations in the day and appreciate the biological rhythm of the group. The CT should involve PE-ST, making them feel concerned about the course content. The involvement of the PE-ST intervenes from the beginning of the training action and lasts until the last minute, so that PE-ST "enters" in the training and implements the skills acquired. Parmentier (2003) notices that PE-STs in training are motivated if it becomes a real actor training feeling valued and secure. He adds training must first: Secure the PE-STs both materially and psychologically.

According to Gervais \& Desrosiers (2005) CT is an important actor for PE-ST applies in a real situation, what they learned in university. According to Carlier (2009a) CT must extract the best practice experiential knowledge to transmit to the PE-ST. This expression of personal theories according Donnay \& Charlier (1996) is a first step in a reflective process, which is essential for PE-ST professionalization.

Parmentier (2003) suggests valuing the PE-STs in their interventions. PE-STs should be expressed: by linking the contents of the training to their experiences or knowledge, they will remember and integrate. In the opposite case, they will be content to stack knowledge they forget very fast. If is desired that the PE-STs express themselves, these interventions must be experienced not as a constraint or judgment but as a recognition of their experience and their knowledge. This valorization intervenes at the beginning of the internship by the interest of the CT to PE-STs, and lasts throughout training by the attentive reaction to their interventions.

The knowledge of CT (22.30\%) indicated in Table 2: whenever the PE-STs talks about:

Academic knowledge: PE-STs state that the CT must respect the training guide. It must also have a theoretical and practical knowledge. It doesn't transmit false information. According to the students to be a trainer, CT must have good training. Some of PE-ST said: "CT must be updated; it must have a theoretical and practical knowledge in all domains" (PE-ST 2). "It must be competent" (PE-ST 5). "It must be competent at scientific, pedagogical and didactic" (PE-ST 15). "CT should help the student in the theoretical preparation of the session” 
(PE-ST 6). "CT must follow the rules of the training; it does not convey false information. It must respect the training guide” (PE-ST 8). “CT must be trained for forming” (PE-ST 9). "He must have a good formation” (PE-ST 13). "CT must be updated; it must be informed of what is happening in the institute” (PE-ST 11).

Experiential knowledge:_Students suggest that the CT sends his practical experience. To do this, it must be experienced. They claim that the CT should be professional in his role. It should not be confused between his sporting training experiences with physical education. Some of PE-ST said: "CT must transmit practical experience his student" (PE-ST 6). "It must be experienced" (PE-ST 9). "It should be professional in his role. It should not be confused between his sport training experiences with physical education” (PE-ST 11). "CT has an important role in the development of professional skills of the PE-STs, it must be experienced to form him" (PE-ST 13). "It must provide information on the practical level” (PE-ST 38).

Teaching style: PE-STs require that the CT must have a teaching style. Some of PE-ST said: "CT must have a teaching method, a training style” (PE-ST 21).

Carlier (2009a) states that CT is located in the three styles of supervision defined by Brûlé (1983). The democratic style (support, confrontation, discussion, clarification) the most used in the post sessions speech. The teaching style refers to advice on the selection of content (management, provocation, evaluation, security, education, demonstration). When CT adopts a posture of listening, they are in experiential non-directive style (interpersonal exploration, consultation and self-expression). According to Carlier (2002), the CT must have a style; develop a training contract, control of interview techniques and evaluation.

The relationship of CT (8.78\%) indicated in Table 2: whenever the PE-STs talks about:

Relationship with the PE-ST: PE-STs suggest that the CTs are aware that the PE-ST is a student. it's in the process of forming not an experienced teacher. Some of PE-ST said: "CT must be informed that PE-ST is a student in the process of forming not an experienced teacher” (PE-ST 11).

Relationship with the administration: The PE-STs consider the CT as a person known within the school. It should help PE-STs to integrate into professional life and to get an idea about his work. It should help them to establish good personal relations with the administrative and students. Some of PE-ST said: "CT is the person who integrates PE-ST to professional life, with the other CT and the administrative personal” (PE-ST 4). "It must be known in high school, everybody know him” (PE-ST 18). "CT must present to PE-ST the work context to have a complete idea about their work” (PE-ST 22).

Relationship with the student: PE-STs considered that the CT is a person who should help them in the classroom management. Across the council, it helps them in the mastery of students. Some of PE-ST said: "CT helps PE-ST in the classroom management" (PE-ST 6). "It provides a procedure to follow to behave with students" (PE-ST 7). "CT helps the student in the mastery of the class” (PE-ST 10).

According to Bremond (2013) the training is approached as an interaction, the CT is an actor among others; it's not a holder of knowledge. The diffusion of knowledge is fundamentally tainted by the exchange in which she will set out. The CT aims is to transmit knowledge and not talking. He must register in the interaction without forgetting the unexpected and indefinite nature of professional situations they exchange.

\subsubsection{Conception of PE-STs of the Role of CTs during Professional Training}

The concerns of PE-STs related to different categories defined during the training courses are in the order: the knowledge of CT (32.39\%), the interventions of CT (30.99\%), the behavior of CT (27.47\%) and the relationship of CT (9.15\%) indicated in the Figure 2.

The results reveal that the major preoccupation of practical accompaniment of CTs that the PE-STs conceive seems to be The knowledge of CT (32.39\%) indicated in Table 3: whenever the PE-STs talks about:

Academic knowledge: Some PE-STs state that the CT is not able to form. It doesn't explain how to write a report of the session. Whenever they ask for help on the didactic knowledge or other, his answer is false or contradictory they studied at the institute. Some of PE-ST said: "CT is not fit for forming; it does not explain how to write a report of the session” (PE-ST 9). "It does not know how to prepare a report” (PE-ST 5). "I think my student is not able to be a trainer" (PE-ST 11). "Every time I ask him for help or lighting didactic point of view or another, his reply is contradictory that I studied at the institute. Most of the time he does not know or he tells me it's wrong” (PE-ST 11). "If I say information, the CT intervenes and tells me that this information is false, but it really is correct” (PE-ST 16).

Experiential knowledge: Some PE-STs claim that CTs require them to respect their personal recommendations even if they are false. In addition, it only has to compare his experience of the PE-ST. Some of PE-ST said: 
Table 3. Analysis grid of conception of PE-STs of the role of CTs during professional training.

\begin{tabular}{|c|c|c|c|c|}
\hline Category & Sub category & The items & Total & $\%$ \\
\hline \multirow{14}{*}{$\begin{array}{l}\text { 1-The behavior } \\
\text { of CT } \\
\text { TOTAL: } 39 \\
27.47 \%\end{array}$} & \multirow{2}{*}{ Assiduity } & Be absent & 6 & 4.23 \\
\hline & & Comes late & 3 & 2.11 \\
\hline & \multirow{4}{*}{$\begin{array}{l}\text { Psychological } \\
\text { condition }\end{array}$} & Neglects PE-ST & 2 & 1.41 \\
\hline & & Gets angry & 2 & 1.41 \\
\hline & & Behaves aggressively & 2 & 1.41 \\
\hline & & Not support the PE-ST & 1 & 0.70 \\
\hline & \multirow{3}{*}{ PE-ST motivation } & $\begin{array}{l}\text { Uses physical and verbal violence with } \\
\text { tudents and requires the PE-ST to do }\end{array}$ & 1 & 0.70 \\
\hline & & Not encourage PE-ST & 2 & 1.41 \\
\hline & & Demoralizes PE-ST & 1 & 0.70 \\
\hline & & Not congratulate the PE-ST despite the effort put & 8 & 5.64 \\
\hline & & Transmits in an understandable way & 6 & 4.23 \\
\hline & & Sets all the time negative remarks & 4 & 2.82 \\
\hline & & Underestimates the PE-ST work & 1 & 0.70 \\
\hline & & & 39 & 27.47 \\
\hline \multirow{7}{*}{$\begin{array}{c}\text { 2-The relationship } \\
\text { of CT } \\
\text { TOTAL: } 13 \\
9.15 \%\end{array}$} & \multirow{3}{*}{ With the PE-ST } & Confuses personal behavior and professional & 1 & 0.70 \\
\hline & & Not behave with PE-ST in the same way & 6 & 4.23 \\
\hline & & Requires the PE-ST to make secondary tasks & 1 & 0.70 \\
\hline & $\begin{array}{c}\text { With the } \\
\text { administration }\end{array}$ & Not present the PE-ST at the administrative personal & 1 & 0.70 \\
\hline & \multirow{3}{*}{$\begin{array}{l}\text { With } \\
\text { the student }\end{array}$} & Not help the PE-ST establish a good relationship with students & 2 & 1.41 \\
\hline & & Pushes the PE-ST to exclude students & 2 & 1.41 \\
\hline & & & 13 & 9.15 \\
\hline \multirow{9}{*}{$\begin{array}{c}\text { 3-The knowledge } \\
\text { of CT } \\
\text { TOTAL: } 46 \\
\text { 32. } 39 \%\end{array}$} & \multirow{5}{*}{$\begin{array}{l}\text { Academic } \\
\text { knowledge }\end{array}$} & Not control what he says & 12 & 8.45 \\
\hline & & Not differentiate between didactics and pedagogy & 10 & 7.04 \\
\hline & & Not know how prepared a report of the session & 8 & 5.64 \\
\hline & & Low theoretical knowledge & 4 & 2.82 \\
\hline & & Transmits his experience of sports training & 3 & 2.11 \\
\hline & \multirow{2}{*}{$\begin{array}{l}\text { Experiential } \\
\text { knowledge }\end{array}$} & Transmits general knowledge & 6 & 4.23 \\
\hline & & Compared his experience of the student experience & 1 & 0.70 \\
\hline & \multirow{3}{*}{ Teaching style } & Has no accompaniment style & 1 & 0.70 \\
\hline & & Uses a traditional method & 1 & 0.70 \\
\hline \multirow{12}{*}{$\begin{array}{c}\text { 4-The interventions } \\
\text { of CT } \\
\text { TOTAL: } 44 \\
30.99 \%\end{array}$} & & & 46 & 32. 39 \\
\hline & \multirow{2}{*}{$\begin{array}{l}\text { Correction of the } \\
\text { PE-ST document }\end{array}$} & Not correct the pedagogical sheet & 7 & 4.93 \\
\hline & & Not correct the class journal & 1 & 0.70 \\
\hline & \multirow{3}{*}{$\begin{array}{l}\text { Observation } \\
\text { of the session }\end{array}$} & Not observe the entire session & 5 & 3.52 \\
\hline & & Not observe the session & 9 & 6. 34 \\
\hline & & Intervene in the piloting of the session & 2 & 1.41 \\
\hline & \multirow{4}{*}{$\begin{array}{l}\text { Advice after } \\
\text { the session }\end{array}$} & No feedback after the pilot session & 8 & 5.64 \\
\hline & & Emits only feedback on mastery of time and class & 1 & 0.70 \\
\hline & & Leaves other teachers to make feedback & 2 & 1.41 \\
\hline & & Not respect PE-ST ideas & 3 & 2.11 \\
\hline & \multirow[t]{2}{*}{ Evaluation } & Not objective in the allocation of the notes of students & 6 & 4.23 \\
\hline & & & 44 & 30.99 \\
\hline Total & & & 142 & \\
\hline
\end{tabular}




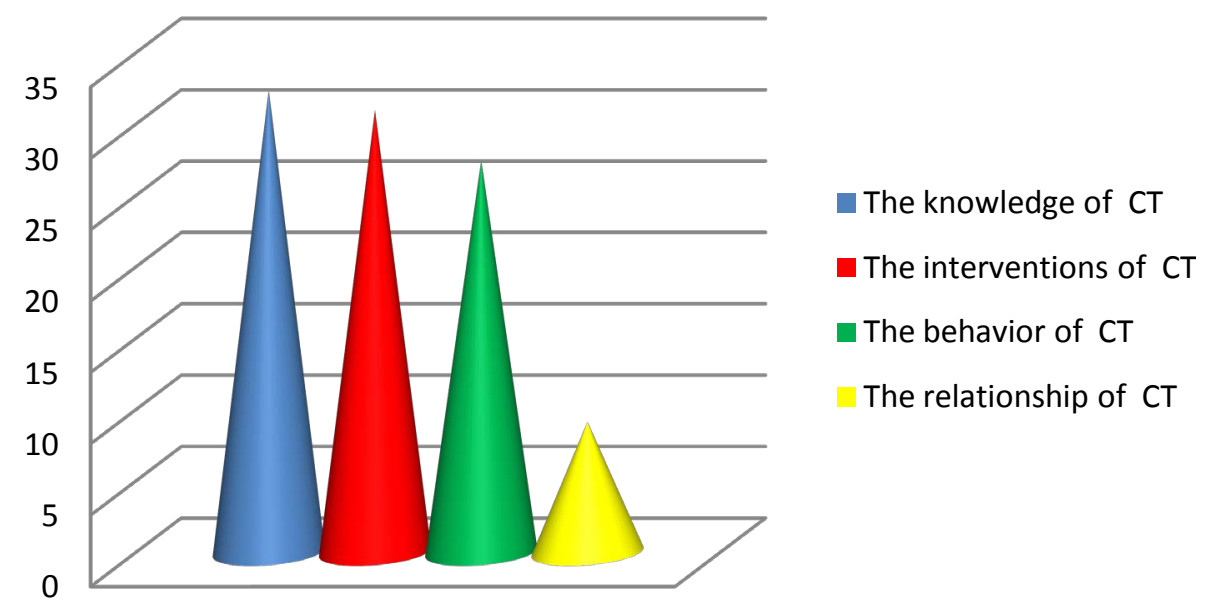

Figure 2. The concerns of PE-STs of the role of CTs during professional training.

“CT makes me respect his personal recommendations even if they are false” (PE-ST 8). "From knowledge, it only compares his experience to mine" (PE-ST 11).

Teaching style: Some PE-STs say that the CT imposes his personal way of working. It uses a traditional method of teaching. Some of PE-ST said: "CT imposes its personal way of working” (PE-ST 19). "I see it uses a traditional method" (PE-ST 40). According to Carlier (2002) CT must take the initiative of establishing the contract with ES: "I, master internship, what are my strengths, my characteristics? What I can honestly and modestly bring you that you will not find elsewhere? “.

According to Gervais \& Desrosiers (2005) in current training programs, internships are presented as experiments to acquire a realistic picture of the working environment and the profession, progressively develop professional skills by mobilizing various resources, including the knowledge gained in academia. They confirm that the internship is an important component of any teacher training program. It allows PE-STs to implement in a real situation, what they had learned at university. Gervais \& Desrosiers (2005) recalled the link between theory and practice, stating that should acquire theoretical knowledge was out of school and the school's contribution is limited to a practical dimension. The internship allows the ES to demonstrate their level of mastery of competencies deemed essential for teaching. They add that the internship is a learning environment, identification and awareness of the requirements for knowledge.

Bremond (2013) require CT to reintroduce the relationship with knowledge and position as an active subject not only a catalyst.

Bali et al. (2014) confirm the difficulties encountered by the trainee teacher influences these behaviors and the tutor takes by responsibility see its role to clarify the objectives of the training.

Interventions of CT (30.99\%) indicated in Table 3: whenever the PE-STs talks about:

Correction of the PE-ST document: Some PE-STs say that the CT does not correct the class journal, pedagogic sheet and cyclic programming. Other students state that the CT only corrects the spelling mistakes, not the content to be taught. Some of PE-ST said: "CT does not control the class journal" (PE-ST 4). "She does not see the pedagogical sheet (PE-ST 40). She does not correct the pedagogical sheet” (PE-ST 25). "Correcting the pedagogical sheet is never correct" (PE-ST 11). "CT only corrects for spelling errors, not the content. The same applies to the cyclical programming” (PE-ST 31).

Observation of the session: Some PE-STs say that the CT does not observe the session. It remains in the dirty teacher or is absent. On the other PE-STs claim that the CT only observed the session from 8am to 10am. After $10 \mathrm{am}$, the student is not working. The CT will observe the conduct of the session only at the presence of the supervisor. The CT leaves the other CTs and teachers intervene during the session. It's enables intervention in the piloting of the session. Some of PE-ST said: "CT does not observe the session, there's no training” (PE-ST 4). "No observations, the CT t always talking on the phone" (PE-ST 5). "He doesn't keep the entire session" (PE-ST 13). "CT doesn't observe the session, it remains in the dirty teacher or sometimes absent, as usual. I am always alone during the training" (PE-ST 32). "CT only observes the session from 8am to 10am. 10am after CT doesn’t work” (PE-ST 34). “Sometimes CT doesn’t observe the entire session after he criticized me on points he 
has not seen” (PE-ST 24). "CT is not interested in the session when the supervisor is not present” (PE-ST 11). "My CT let the other CTs and teachers intervene during the session" (PE-ST 7). "CT intervenes in piloting the session in all situations" (PE-ST 18).

Advice after the session: Some PE-STs say that the CT leaves the other CTs and teachers intervene in feedback. It doesn't respect the feedback time. Sometimes there is no feedback. It transmits council on the preparation of the sheet; it didn't transmit practical instructions related to the mastery of the students. The CT insists on things that are not important. He imposes his ideas during the discussion, it makes me fault. Some PE-STs require that the CT corrects and guide them. Other PE-STs notice a difference between what the CT demand and the supervisor. Some of PE-ST said: "CT let the other CT and teachers involved in my session and feedback" (PE-ST 7). "The feedback is reduced in time and information. CT transmits only advice related to the mastery of time, class and educational voice. Sometimes the CT not does the feedback" (PE-ST 38). "In the feedback, it only provides guidelines on the preparation of the form, does not give practical instructions related to the mastery of students" (PE-ST 1). "CT insists on things that do not sound important. It is true that we must have an idea about their absences but the case remains secondary spots. The CT don't make most important that my intervention, my advice, my choice situations. Generally he gets little (PE-ST 21). "CT does not give a more during feedback. He imposes his ideas during the discussion" (PE-ST 4). "If CT notices something that does not work, as an example if it does not like the job, she said, no feedback and she leave. She always talks about the lesson plan, poorly classroom organization, poorly managing time and space, wrong choice of situations. By cons I find my work a lot" (PE-ST 27). "CT does not consider my opinion and my choice” (PE-ST 40). "Each time CT makes me guilty, they are commonplace errors. He's a God, there's no fault. He considers me a confirmed teacher not a student. CT must correct me, guide me and tell me to do; I'm here to learn" (PE-ST 24). "There is a difference between what CT application and that the application supervisor" (PE-ST 3).

Evaluation: Some PE-STs discover a difference between the attribute notes to the students and that the ballots. PE-STs report that the CT requires them attributed a note about student discipline. In addition, they claim that the CT is not objective in the evaluation of students. Some of PE-ST said: "It's me who did the evaluation and attributes the note to students but after I saw another notification on grade reports" (PE-ST 29). "I noticed a delay between the notes that I attribute to the students and real notes" (PE-ST 5). "CT forces me to attribute the note on student discipline (PE-ST 11).' I'm an excellent PE-ST, I know myself. The note attributed by the framer does not reflect my effort” (PE-ST 34).

Carlier (2009b) states that CT refers mainly on personal experience of teachers. First, Carlier (2002) suggests CT to increase the confidence of PE-STs by allowing them to appropriate the content and behavior models to interactive classroom management. Second, ask PE-STs to analyze and evaluate the practice by pointing the methods to cross the barrier of experiential knowledge.

Gaudreau et al. (2012) confirm that more than the teacher's effectiveness beliefs are weak, more than inappropriate behavior in class are high. Thus, the more inappropriate behaviors are frequent, more teachers cast doubt on his abilities, which makes it more vulnerable to stress and professional burnout.

The behavior of CT (27.47\%) indicated in Table 3: whenever the PE-STs talks about:

Assiduity: Some PE-STs claim that the CTs arrive late. There's no feedback and does not transmit instructions. Some of PE-ST said: "Every day CT arrives late, I'm obliged to wait or calling by phone to see if it comes or not" (PE-ST 40). "CT arrives late; in addition there is no feedback" (PE-ST 9). "CT is always late (sometimes absent)" (PE-ST 20). "CT is present absent. The only role that knows to do is signing on educational sheets. There's no feedback and does not transmit instructions” (PE-ST 2).

Psychological condition: Some PE-STs claim that the CTs demoralize them with negative remarks. They require PE-STs to make a stain with an aggressive manner. Some student said that are not independent during training. Some of PE-ST said: "CT never told me the positive feedback, it's always addressed with a wrong way with the trainee until demoralize" (PE-ST 11). "She's still angry and she always speaks in a bad way" (PE-ST 25). "CT forces me to do tasks that he does not when he teaches. It forces me to tracing the ground of an aggressive manner" (PE-ST 11). "CT is not autonomous in training. He takes opinion of the other CT and will not support me” (PE-ST 24).

PE-ST motivation: Some PE-STs claim that the CT underestimates their work. It doesn't encourage them to progress. Some of PE-ST said: "CT underestimates my work" (PE-ST 5). "CT does not encourage working better and evolving. It makes me demoralize” (PE-ST 25). "Despite the effort, there’s no congratulation (PE-ST 27). She always says nothing works" (PE-ST 34). "CT is opposed to the positive comments that the supervisor told 
(PE-ST 11). Communication skills: Some PE-STs report that the student has a language not appropriate to training. Some of PE-ST said: “CT has a very poor language in relation to the training that I learn” (PE-ST 20). “CT always talks about the negatives point” (PE-ST 25).

According to Martineau \& Vallerand (2005) novice experiencing difficulties related to hourly conditions, task, teaching discipline, constant adaptation, security processes. This greatly harms them because already in September, students will be excessive stress. A temporary solution would be that the school administration makes available to the new teacher, with a talented colleague or a mentor (Martineau \& Vallerand, 2005).

Martineau \& Vallerand (2005) propose that the administrative team attaches importance to the working conditions for beginning teachers to enable them to successfully enter the profession.

Gold (1996) distinguishes between two categories of support: support for teaching ("instructional support”) and psychological support. Support for education concerning assistance to the acquisition of knowledge, skills and strategies needed to succeed in the classroom and within the school. This support may consist of an instrumental assistance, informational (advice, information) and evaluative (feedback). Psychological support, reporting a humanist perspective, is designed to satisfy the personal needs felt by beginners. It includes both emotional support (empathetic listening, encouragement, confidence), the evaluative support (need to be reassured and confirmed) and support for the development of identity (self-confidence, feeling of efficacy, positive self-esteem and management stress). Psychological support can also help beginning teachers to develop resilience to difficult conditions for entry to the professional life (job insecurity, insecurity, heavy workload, difficult class groups), to develop a positive self-image as a teacher and maintain a positive relationship to the profession.

According to Parmentier (2003) CT should reassure PE-ST on the conditions of operation of the training and about the relevance of their presence. This security intervenes from the start and should be confirmed throughout the training. In addition, CTs will allow the PE-ST to become actors of their own training. It confirms that PESTs will be active, the more they store the content of the training. PE-STs must be involved throughout the course.

The relationship of CT (9.15\%) indicated in Table 3: whenever the PE-STs talks about:

Relationship with the PE-ST: Some PE-STs find that the CT doesn't behave the same way with all PE-STs. It doesn't behave with the PE-ST as a future colleague, it leaves the other teachers disrupts their relationship. Some of PE-ST said: “At first I thought that will be easy to integrate into the life of the training but I found the opposite. CT does not behave with the same way with all PE-ST. It promotes during the feedback on each other and makes it just because his parents work at the department” (PE-ST 40). "CT must behave with the PE-ST as a future colleague, do not let him ask to go buy a coffee” (PE-ST 1). "There's a teacher who tries to make a disturbance in my relationship with the coach. He let it" (PE-ST 6). "CT believes that the student is a true teacher who has skills and experience (PE-ST 27).

Relationship with the administration: Some PE-STs report that the CT not presents them at the administrative staff. Some of PE-ST said: "CT does not fulfill his role as CT. CT had not introduced me to the administrative staff. He asks us to work on the place of the PE-ST absent” (PE-ST 11).

Relationship with the student: Some PE-STs say that the CT requires them to exclude and use verbal and physical violence with students. Some of PE-ST said: "In the case of punishment of students, the first decision that CT prefers it is the exclusion of the student” (PE-ST 18). "CT put me the responsibility to collect money to the school team but I refused. He accused me of not mastering the class. After collecting money from students, CT noted absentee students who have not brought money. CT uses verbal and physical violence with students and gives me the green light to do like him. He teaches my class an extra hour where students practice three hours a week and that their games. Students find my session less motivating than him. It puts me in difficulty with students" (PE-ST 11).

According Mukamurera et al. (2013) the beginning in the profession remains often problematic and stressful. Many students live what is commonly called the shock of reality. This shock has a destabilization effect, disappointments and questioned. He characterized the feeling of survival, to feel the pedagogical incompetence or impotence and vulnerability, and to constantly adapt to a complex and changing environment. During their initial training, students should suddenly go from student status to the teacher who is engaging in the professional of teaching (Mukamurera, 2005; Bali, 2014).

According to Martineau et al. (2010) the professional integration of teachers is a difficult time of life at work, during which the PE-ST is confronted with a multitude of experiences and new situations that must adapt quickly. Without support, it is very difficult for novice teachers to get through this crucial level of professional 
development.

According to Perez-Roux (2012) recognition enhances the interpersonal skills of the individual and the moral principles underlying. These are essential for CT and PE-ST to operate. The sharing of values between the CT and PE-ST is a form of recognition; it's a report to the profession which organizes daily activities. Apart from the relational articulating self-esteem and recognition of others, the biographical dimension means for the individual to be recognized for what it is and for what he has experienced. Also, PE-ST often feels lost because they do not know the functioning of the school or the habits of teachers in place and must adapt to these innovations (Martineau et al., 2010).

According to Martineau \& Mukamurera (2012) it’s essential that PE-ST appropriate operating rules, expectations and culture of the community to exercise the professional role and be accepted as a member. The introduction of ES refers to the adaptation and mastery of the professional role in the development of knowledge and skills specific to the profession. This is knowledge "teach the class", to become effective in the work according to professional skills expected.

Ndoreraho \& Martineau (2006) report that the difficulties experienced by PE-ST during their professional integration period such as stress in his functions and teaching in an unfavorable environment negatively affect their interest in applying the teaching profession. In the following, these difficulties are the cause of their profession abandonment.

According to Bremond (2013) the CT said they did not understand what they could bring to PE-STs who experiencing difficulties to control her students. Whereas the CTs considers that PE-STs was leaving an education that develops the management class. Martineau et al. (2010) argue that the lack of experience of beginning teachers makes it difficult to solve everyday problems particularly the classroom management. The CT spell out that the problems with the organization are the symptom of a particular difficulty to the PE-ST that should be questioned.

These results are justified by Dugal (2003) who asserts that the CT want to help and secure the PE-ST they have the charge to accompany; which is reflected by preoccupations oriented to the organization and the classroom management as to the content to be taught.

In the same direction, results of studies conducted by Buyse et al. (2008) emphasize the importance of establishing a positive relationship between teacher and pupils with difficult behavior in the classroom. They point out that the intervention should not be directed solely to the student, as is often the case. According to Hamre \& Pianta (2005), students should concentrate efforts on the climate of the class, as an important influence on the development of school behavior problems. They add that the teacher must establish a relationship of trust with students by using effective classroom management practices.

(27.5\%) PE-STs respond that there's no difference between the conception of PE-ST of the role of CT by PE-STs before and during the internship. Some of PE-ST said: CT arrives on time, put at my disposal the available material, behaves well and transmits didactic and pedagogical advice (PE-ST 5). There is not much difference between the conception and the real because I'm satisfied and I learned from the experience of CT. he transmits any information of students, equipment and the high school. CT makes her role; she evokes the small details that I do not take into account. Side of the relationship, she respects me (PE-ST 6). At the beginning of the academic year I'm lost but with the help and advice CT I arrived to take place in the professional life. No difference in the establishment, there is a good relationship between physical education teachers. We are a family. At the first school semester CT correct pedagogical voice and correct the behavior. During the second semester CT is interested to managing time and space, student learning and it gives solutions to the conception of the session (PE-ST 10). No difference but ISSEP must do refresher training to innovate the level of knowledge of CT (PE-ST 15).

According to PE-STs (72. 5\%), there's a difference between the conception of the role of CT by PE-STs before and during the internship. For some PE-ST, there is not a CT in the course. In addition, CT does not fulfill its role. There's only CT who control the presence and sign on pedagogic sheets. According to another student, there is a contradiction between academic training and internship. CTs focus advice on the pedagogical side and forget the didactic side. PE-STs request for CTs to really help. Some of them hated the framer, the internship and training. Some of PE-ST said: A 180 degree offset. Actually there's not CT during the internship, there's a CT who control the presence and sign on pedagogic sheets (PE-ST 2). There's a difference between conception and reality, there's a contradiction between academic training and internship. CT focuses the advice on the pedagogical side and forgets the didactic side (PE-ST 4). CT does not work properly (PE-ST 19). It does totally 
oppose, CT will help me to form, but it makes me feel like a student. Now I hate my CT, the training and education in the school (PE-ST 20). There's a difference between conception and reality. I imagined that I will find a CT who helps the PE-ST. I found the opposite, a CT who thinks that the PE-ST is a teacher confirms (PE-ST 27). There is a difference between conception and the real, the CT does not make his role, and he mixes professional with emotions and relational. I'm very shocking reality. I never imagined this disaster. I work with my own effort, no person accompage me (PE-ST 32). ). There's a wide difference between what I imagined and I actually met him, I am completely disappointed. There is no link between what I conceived, and what I found (PE-ST 25).

By Paquay \& Perrenoud (2002) the majority of CTs come from the world of teachers. They were school teachers, or college or high school, sharing between teaching in their establishment and training function.

Paquay \& Perrenoud (2002) point out that the title of CT is ambiguous. This title does not match what is recorded in administrative documents, talking teacher, methodologist, psychologist and educationalist.

Mouton (2009) finds that there is a great illusion to believe that CT is able to respond effectively to the requirements of a trainee engaged with a problem situation. He added that the CT is neither a scientist nor an expert, but a professional who organizes a training environment in a role to introduce PE-STs in the teaching profession. In this approach, Leriche et al. (2010) believe that internships are not sufficient to promote the development of professional teaching skills. The success of this company seems strongly associated with accompanying practices implemented by the CT. Bergevin (2007) points out that mentoring requires the selection of mentors based on specific criteria. He added that the role of mentors in the dyad remains to be clarified and the training that he receives to fulfill its role. By Rocque \& Bernier (2013) the world of modern education runs another form school dropout than experienced by students: the teachers. The profession Beginners often leaves work in their first years of teaching.

In fact, Fontaine et al. (2011) estimate that 20\% in New Zealand the number of new teachers leaving the profession secondary school in their first five years of teaching. For her part, Finland number $10 \%$ to $12 \%$ the profession's dropout rate in the first four years. Gohier et al. (2007) make the same observation for Quebec, North America and Europe with a dropout rate amounting to $20 \%$. In the US, the dropout rate would be $30 \%$ to $50 \%$.

Maela (2002) states that today those who formulate an accompanying demand are no longer those who expressed a desire for personal development; these are people facing existential malaise, imbricated in situations where it's difficult to separate the individual problem of the social context. Maela (2002) concluded that the relationship was no longer reducible to a dual relationship between CT and PE-ST; it must take into account the relationship which integrates with a social context at large.

\section{Conclusions}

Remember that we have described here only part of results of our doctoral research, which is still in progress. Our findings are partial because they only reflect the vision of part of the PE-ST involved in the conceptions of the role of the CT and the accompaniments practices. Nevertheless, in light of our data it's possible to declare that the accompaniments practices in Tunisian schools are not very active in providing support to PE-STs. We are far from an ideal situation and the accompaniments practical folder must continue to assert its priority dimension to the school environment. This is necessary because we find great variability in the role of CT and academic programs and yet there is no formal profile in Tunisia to mark the standards of school actions.

Also in connection with the accompanying practices currently in Tunisia, our results suggest that they pursue different aims, some more prevalent than others. Also we see that the accompaniments practices do not offer quite a variety of choices for content, intervention and support. One thinks of the necessity of the training workshops, mentoring and knowledge transmitted. It is, however, regrettable that the accompaniments practices do not include valuation task for PE-ST.

In summary, the problems regarding content, intervention and support seem that obviously have a negative impact on the professional training of teaching students, which is not beneficial for insertion in schools and the teaching profession. This finding should hold the attention of officials of the training and get them to support the realization of improvements that some of our respondents consider as necessary to increase the accompaniments practices.

Thus, we can take the risk to say that the practices of accompaniments record of Tunisian PE-STs are called for new developments in the near future. Data from beginning teachers bring probably lighting and complementary lines of inquiry for improving the role of the student and of accompaniments practices. 


\section{References}

Bali, N. (2005). “Theory and Practice” Articulation in the Training of Tunisian Student Physical Education Teachers. The Journal of Research and Training, 49, 135-150.

Bali, N. (2013). Teachers’ Thought Processes: The Case of Tunisian Gymnastic University Teachers. Creative Education, 4, 158-164. http://dx.doi.org/10.4236/ce.2013.47A2020

Bali, N. (2015). The Tunisians Cooperative Teachers and Student Teachers' Conceptions about Class Management Skill. Creative Education, 6, 87-99. http://dx.doi.org/10.4236/ce.2015.61008

Bali, N. et al. (2013). The Conceptions of Authority of Tunisian Physical Education Cooperative Teachers and Student Teachers. Conference Proceedings of the 7th Biennial ARIS, France.

Bali, N. et al. (2014). The Conceptions of Integration of Tunisian Physical Education Cooperative Teachers and Student Teachers. Creative Education, 5, 279-289. http://dx.doi.org/10.4236/ce.2014.54037

Bali, N., \& Souissi, K. (2015). Comparative Study of Physical Education Students Teachers Style Interventions Teaching Styles Skill. Creative Education, 6, 100-113. http://dx.doi.org/10.4236/ce.2015.61009

Boulet, M., \& Pharand, J. (2008). Concentrated Accompanying of Student Teachers. Quebec: PUQ.

Boutin, G. \& Camaraire, L. (2001). Introduce and Mentor of Student Teacher. Practical Guide for Teacher-Trainer, Montreal, Publishing News, Bujold.

Brau-Antony, S., Mieusset, C., Lenfant, A., \& Miot, C. (2011). Analyze the Work of Tutors Beginning Teachers. Continuing Education, 186, 175-185.

Bremond, C. (2013). The Trainer He Knows What He’s Talking? New Review of Psychology, 1, 241-252.

Buyse, E. et al. (2008). Classroom Problem Behavior and Teacher-Child Relationships in Kindergarten: The Moderating Role of Classroom Climate. Journal of School Psychology, 46, 367-391. http://dx.doi.org/10.1016/j.jsp.2007.06.009

Carlier, G. (2002). Supervise of Trainee in Physical Education: Tags for a Function in the Process of Professionalization (pp. 96-111). Belgium: Catholic University of Louvain.

Carlier, G. (2009a). Accompany and Training of Tutors in Physical Education. The Experience of the Catholic University of Louvain (Belgium). Education and Francophonie, 37, 68-88. http://dx.doi.org/10.7202/037653ar

Carlier, G. (2009b). Supervise Trainees in Physical Education: A Tag for a Function in Professionalization Pathway. Revue phénEPS/PHEnex Journal, 8, 96-111.

Desbiens, J. F., Borges, C., \& Spallanzani, C. (2009). Educational Supervision in Physical Education. Education and Francophonie, 37, 1-5. http://dx.doi.org/10.7202/037649ar

Dugal, J.-P. (2003). Consulting Initial Teacher Training. Interest and the Pedagogic Knowledge for Mentoring Student Teachers in EPS. Doctoral Dissertation, PhD in Sports Science, Paul Sabatier: Université Toulouse III.

Faingold, N. (2006). Training of Trainers in the Analysis of Practices. Research and Education, 51, 89-104.

Fontaine, S. et al. (2011). New Teachers’ Career Intentions: Factors Influencing New Teachers’ Decisions to Stay or to Leave the Profession. Alberta Journal of Educational Research, 57, 379-408.

Gaudreau et al. (2012). Positive Management Class of Situations: A Model of In-Service Training to Help Primary Teachers to Prevent Challenging Behaviors of Students. Children in difficulty, 1, 85-115.

Gervais, C., \& Desrosiers, P. (2005). The School, Place of Teaching Training: Question and Marks and for Supervision of Trainees. Canada: The Laval University Press.

Gohier, C., Chevrier, J., \& Anadón, M. (2007). Future Teachers’ Identity: Between an Idealistic Vision and a Realistic View. Revue des Sciences de l'Éducation de McGill, 42, 141-156.

Gold, Y. (1996). Beginning Teacher Support. Attrition, Mentoring, and Induction. In J. Sikula, T. J. Buttery, \& E. Guyton (Eds.), Handbook of Research on teacher Education (2nd Edition, pp. 548-594). New York: Macmillan Library.

Hamre, B. K., \& Pianta, R. C. (2005). Can Instructional and Emotional Support in the First-Grade Classroom Make a Difference for Children at Risk of School Failure? Child Development, 76, 949-967. http://dx.doi.org/10.1111/j.1467-8624.2005.00889.x

Jorro, A. (2007). The Alternation Research and Professional Training Ground. Research and Training, 54, 101-114.

Leriche, J., Desbiens, J. F., Dugal, J. P., \& Amade-Escot, C. (2010). Analysis of the Accompanying Responsibility in Quebec and France: A Look at the Post-Lesson Interviews with the Ecology of the Classroom. Review e-JRIEPS, 71-98.

Lévesque, M., \& Gervais, C. (2000). Professional Integration: A Step to Succeed in the Professionalization of Teaching. Education Canada, 40, 12-15.

Maela, P. (2002). Accompaniment: A Nebula. Permanent Education, 153, 43-56.

Maela, P. (2009). Around the Word Accompaniment. Research and Training, 62, 91-107. 
Martineau, S., \& Mukamurera, J. (2012). Overview of Major Programs and Support Systems for Professional Integration in Education. Phronesis, 1, 45-62. http://dx.doi.org/10.7202/1009059ar

Martineau, S., \& Presseau, A. (2003).The Sense of Professional Incompetence of Teachers Early in Their Careers and Support Employability. Brock Education, 12, 2-6.

Martineau, S., \& Vallerand, A. (2005). The professional Integration of Teachers: A Challenge for Schools, a Challenge to the World of Research. Presented as Part of Seminars Crifpe, Power Point recovered from the Centre's website: http://www.insertion.qc.ca/cnipe_2/spip.php?article81

Martineau, S., Portelance, L., \& Presseau, A. (2010). Mentoring as a Support System for the Employment of Teachers. Communication presented in the International Conference "Complex thinking: Challenges and Opportunities for" Education, Research and Organizations, 1, 2-8.

Mouton, J.-C. (2009). Form Analysis Consultancy Master Trainer Training of Accompanied Practice. Research and Education, 62, 65-76.

Mukamurera et al. (2013). The Teacher Induction Programs in Québec School Boards: Overview and Assessment of Actors. Education and Training, 29, 13-35.

Ndoreraho, J. P., \& Martineau, S. (2006). A Problematic Beginning of the Teaching Career.

Parmentier, C. (2003). The Bulk of Training (pp. 37-305). Paris: Organizing Editions.

Perez-Roux, T. (2012). Identity Construction of New Teachers: What Recognition of Others to Known as a Professional? Educations \& Research Journal, 7, 69-84.

Rayou, P., \& Ria, L. (2009). Train New Teachers. Various Statutes, Organization and Professional Knowledge. Education and Corporate, 1, 79-90.

Rocque, J., \& Bernier, P. (2013). The Dropout Phenomenon among Teacher's Consequences, Impacts and Considerations (pp. 1-26). Winnipeg: University of St. Boniface.

Trohel, J. et al. (2004). The Dynamic of Interactions Tutors Students Experiencing Educational Advice. Knowledge, 5, 119140.

Vandercleyen, F., Delens, C., \& Carlier, G. (2013). Supervision Styles of Tutors in Physical Education: Consideration of the Emotional Experiences of Trainees during a Post-Lesson Interview. EJRIEPS, 61-99.

Zayed, W., \& Bali, N. (2015). Introduction of Student Teachers in Tunisian Secondary Schools: A Discourse Analysis of Cooperative Teacher. Creative Education, 6, 359-368. http://dx.doi.org/10.4236/ce.2015.63034 